International Research Journal of Engineering, IT \& Scientific Research
Available online at https://sloap.org/journals/index.php/irjeis/
Vol. 6 No. 3, May 2020, pages: 1-8
ISSN: 2454-2261
https://doi.org/10.21744/irjeis.v6n3.914

\title{
Importance of comprehensive reading: its value in basic
}

\author{
Romina Adelina Quevedo Alava ${ }^{a}$ \\ Esthela María San Andrés Laz ${ }^{\text {b }}$ \\ Josefa Katiuska Toala Palmac ${ }^{c}$ \\ Enrrique Byron Ayón Parrales d
}

Article history:

Submitted: 27 March 2020

Revised: 18 April 2020

Accepted: 09 May 2020

\section{Keywords:}

critical analysis;

reading comprehension;

strategies;

teacher support;

\begin{abstract}
A study of the comprehensive reading, its importance and the basic value of an educational institution in the province of Manabí was conducted, it was investigated what is the impact on students, in which it benefits them to understand what is found in the pages of a text, how to broaden its criticality, the concentration of reading, writing and oral skills, to have a better communication and how reading influenced values, it was elaborated in a research way with the help of ICT, not practical, with the inductive method deductive, finally, the linguistic norms, pauses, emphasis, vowel sounds that are used when reading are analyzed, such as strategies that can be used for images, graphics, mental or conceptual maps, together with teacher support inside or outside the classroom, coordinate the ways of studying the topics because each student thinks and analyzes differently.
\end{abstract}

International research journal of engineering, IT \& scientific research (C) 2020. This is an open access article under the CC BY-NC-ND license (https://creativecommons.org/licenses/by-nc-nd/4.0/).

\section{Corresponding author:}

Romina Adelina Quevedo Alava,

Pontificia Universidad Católica, sede Manabí, Portoviejo, Ecuador.

Email address: rquevedo9337@ pucem.edu.ec

\footnotetext{
a Pontificia Universidad Católica, sede Manabí, Portoviejo, Ecuador

b Pontificia Universidad Católica, sede Manabí, Portoviejo, Ecuador

c Pontificia Universidad Católica, sede Manabí, Portoviejo, Ecuador

d Pontificia Universidad Católica, sede Manabí, Portoviejo, Ecuador
} 


\section{Introduction}

The evaluation of processes as a teacher improvement strategy is essential, for the optimization of the quality of education, oriented to the diagnosis of pedagogical practices. In some countries, especially the underdeveloped, education presents countless difficulties. These include the weak budget that governments manage for education, lack of teacher training, and teacher status that is not valued at this time.

Some studies carried out in Spain, review that the students of the high school master do not agree with the programming of the didactics in the classes, in other words there is no order between the theory and the practice of the subject taught. Also the actions of some teachers of individualistic and traditionalist character in certain pedagogical practices.

The importance of communicating the knowledge acquired has always been the fundamental axis of civilization, images, and symbols in stone scrolls and many variants show that the understanding and interpretation of reading improves the quality in society and drives the development of the world as we know. When inquiring and establishing reading comprehension in the teaching and learning process, it is important for the fulfillment of the educational objectives proposed at the national level that leads to the construction of a new student profile that covers cognitive expectations and demands with school quality (Anmarkrud \& Bråten, 2009; Aksan \& Kisac, 2009; Logan et al., 2011).

It is convenient for teachers to discuss strategies for analysis and observation of argumentative dynamics in discursive enunciation with students (Lawton, 1996; Choudhury \& Black, 1993; Nurmi et al., 1995). The idea is that the student assumes with autonomy and freedom the cultural exercise of the reasoned argument as a learning challenge. Classroom education must be conceived and thought, from the discourse in its various facets, delving into activities that promote the understanding of meaningful academic texts from the eyes of the world, to discover its practical value in existence (Sánchez \& Brito, 2015). The analysis strategies in the reading comprehension drive the fluid communication of the context of the reading, allows to discover the precise focus of the text and the multiple activities that can be raised in the classroom more dynamically.

Reading should be considered as a strategy of knowledge and expression that begins with the desire to know the content of the pages Estévez (2018), states that "consider reading as one of the forms of happiness, valid in itself as a reason, when we ask our students to read a text, it must be for a pedagogical purpose "(p. 5). Reading besides being one of the portals with which we change the world, situations, or contexts that give us joy and unforgettable experiences within the classroom has an educational purpose that is consolidated in the real application of the issues. In Manabí it becomes vitally important to design and implement dynamic strategies of comprehensive reading, which generates important changes to those who receive it, Alcívar et al. (2018), comment "When the text is scientific it requires a technical structure, this it does it methodologically and for linguistics, different from literary, informative and lyrical texts". When linguistic procedures are added, invaluable academic results are obtained, it would be possible to awaken in the student, a search for continuous improvement that will have an impact on performance and significant performance in all areas of study based on logical analysis.

\section{Materials and Methods}

The present work was carried out in a non-practical investigative way, the inductive-deductive method was used since it allows to investigate new reading skills and is the bridge to reach the understanding and the critical analysis of the reading, it was carried out through observation and using the method of analysis of renewed bibliographic material using ICT to obtain these resources as articles, thesis, books in magazines and certified repositories as reliable sources for the study of the subject (Maimun et al., 2018; Cuéllar-Franca \& Azapagic, 2015; Sivarajah et al., 2017; Beske et al., 2014).

\section{Results and Discussions}

\subsection{Didactics}

The didactics applied in comprehensive reading is the nexus that the student has with the book, the argument that can be taken after examining its pages, is the way the student obtains knowledge, is part of the individual logical thinking 
of the student body, The teacher acts as a guide and provides the necessary resources so that the construction of the reflection is more feasible and takes less time, the student doesn't need to use complicated phrases at the time of expressing himself, he must only be concise and with clear foundations so that all Those present understand it.

\subsection{Levels of knowledge in reading}

Reading has its levels in knowledge which exert a different and related function at the same time (Palomeque, 2012) refers that in the Critical Level exposes the content made by the author, supported by his routine of life and is oriented to be conclusive and instills values, Literal Level is located in the grammatical content of a locality, culture, contexts, and versatility of the same, it can occur in basic or depth reading, the inferential level is concentrated in understanding and elucidating what that the author presented in his pages, the reader combines the first levels in an abstract way and fosters the desire to learn to move further than what is projected in writing.

\subsection{Grammar of the text}

The grammar or linguistics of the text is supported by two bases coherence and textual cohesion Huerta (2010), affirm that coherence is the primary thought, the same one that intertwines the other opinions issued by the author and formulates a concordance of facts so that in the end the reader has the pleasure of replicating in his mind everything that has happened, textual cohesion is related to the argument because this analyzes every detail in the document, must be following the grammatical norms, its interrelated content even when it contributes new ideas must be illustrated in an understandable way for any kind of reader. At the time it is only read by reading, the entire content of research, inquiry, truthfulness is left behind, or it can be in other cases non-existent or dreamers with interpretive tones, consolidated with a practical grammar accessible and known by the participants who are involved In groups with no idea many times that they are doing it, the teacher is the link in this interpretive process.

In the analysis of a text, you must understand what the book wishes to convey. Uribe \& Carrillo (2014), state that the act of reading and writing is indissoluble due to the constant exchange of information between varied transmitters and receivers, where each code and message implies complex coding and decoding processes that allow us to build meaning and achieve dialogic interaction between authors and readers "(p. 275). The potential of students is based on the interpretation and structures of their ideas, many based on what they capture in the books, developing better retention and concentration.

Continuing our work we can say that oral expression is indeed very important for reading comprehension Solís (2016), affirms that "It is one of man's abilities to manifest his thoughts, feelings, and opinions to other people "(p.31). It is the vision of the student with his points of view, the public presentation of what his brain quickly captures, all the emotions within the demonstration, this is where the reader assumes a role of gestural symbolisms before what happened transmits the happiness or sadness that you felt or the emotion to discover new stories, the oral expression is to share with others the knowledge gained.

Comprehensive reading follows steps of interaction with the text, interpretation of words, and decoding of figures. This means that the amount of incoming information exceeds the ability of our nervous system to process it in parallel, so mechanism is necessary neuronal that regulate and focus the organism, selecting and organizing perception, and allowing stimulus to give rise to an impact; that is, that it can develop a neural process electrochemically. This neuronal mechanism is attention, whose capacity could be developed progressively from childhood to adult and whose activity is not only based on regulating the entry of information but would also be involved in the information processing itself (Flores, 2015; Hendrickx et al., 2016; Joyce \& Early, 2014; Dietrich et al., 2015).

The information acquired is interpreted differently depending on each student, social environment and the relationship with which he felt at the time of reading, this definition is like seeing the same painting from two different angles, the reality is variable depending on the stimulus in the At the moment the student is reading, his imagination is also involved, his vision may vary, or the conception of the concept of words, a student who comes from the field identifies the word banana as a vegetable and that of the city as the fruit.

\subsection{Strategies for critical thinking}

This pedagogy used correctly at the time of reading, this generates cognitive suitability based on the analysis process that builds knowledge and deciphers the content of the text Moreno \& Velázquez (2017), refer that to achieve

Alava, R. A. Q., Laz, E. M. S. A., Palmac, J. K. T., \& Parrales, E. B. A. (2020). Importance of comprehensive reading: its value in basic. International Research Journal of Engineering, IT \& Scientific Research, 
grammatical mastery in Students use sources observation, judge, discriminate determine questions with applicable answers, use eloquent strategies, concept maps, synthesis of what was understood in the reading, or the analysis known as SPRI (Situation, Problem, Resolution, Information) are suitable instruments that the teacher has to facilitate deep thinking, the same that with clear and simple ideas can convey the thoughts or formulations found in the text. When placing the students in the study the representative texts, these must be related to the environment in which they live so that the aforementioned has greater logical coherence and the values that are linked in the implicit and explicit learning process are understood and applied in the society, as a fundamental part the teacher must be the motivator so that the result of the reading is optimal Duque et al. (2011), argue that reading is a form of mental description with a similar sense, this happens thanks to the storage of ideas that In many occasions it is a reference of their experiences, these designs provide the ease of understanding the content and remembering them if they have had a positive impact on them.

A strategy to improve reading comprehension is that when a book is read, it is doing so deliberately to understand the words, but they're somewhere know it's meaning Knorr (2012), states are wise to pay attention to by texts that are to say all the verbal elements (titles, references, place, and date of publication) or iconic (photographs, graphics, maps) that accompany or extend the meaning of the main text, so they become auxiliary for your understanding (Álvarez, 2016). The observation of the outline of the book is important and support with an online dictionary or tool is essential since it allows to translate and at that time a range of interpretations is opened or when elaborating a conjecture can be taken to a critical and meaningful analysis of the approaches proposed at the beginning.

Reading with a rational sense must take a sequence an unlisted order that serves as a support to relate the fictional with reality (Padilla \& Cordova, 2016) mention that when describing the paragraphs in the mind and mixing them with the imagination of the individual, you can find the judgments that the author wanted to show or the similarities and divergences that are proposed in a book, however, when the text is of an academic order you can project the possible solutions, reach the answers to the problems found or generate new cognitive advances, make a continuous reading more and more interesting for the reader and motivating for the author.

A skill for reading comprehension and source of wealth in logical notions are the reading groups Álvarez (2016), says that "In a reading club, the reading stimulus is increased in all cases, both for those who were already readers and for those who they start (Álvarez, 2016). The overall interpretation of the narrative of a text, directly related to the critical and reflexive analysis of what is manifested on each page is shared in a group, can be in narrative, literary, expository, argumentative, descriptive, instructive, encrypted or Braille text, the sense of reading with the use of the imagination of the reader who is responsible for hearing the text instead of looking at it. The analysis enhances the action of socializing rationally and is presented as the culmination of active reading and mutual interaction.

\subsection{Analysis of results discussion}

The analysis of comprehensive reading and strategies as resources used to improve understanding in texts, expressed by various authors, are detailed. It is shown in figure 1 . 


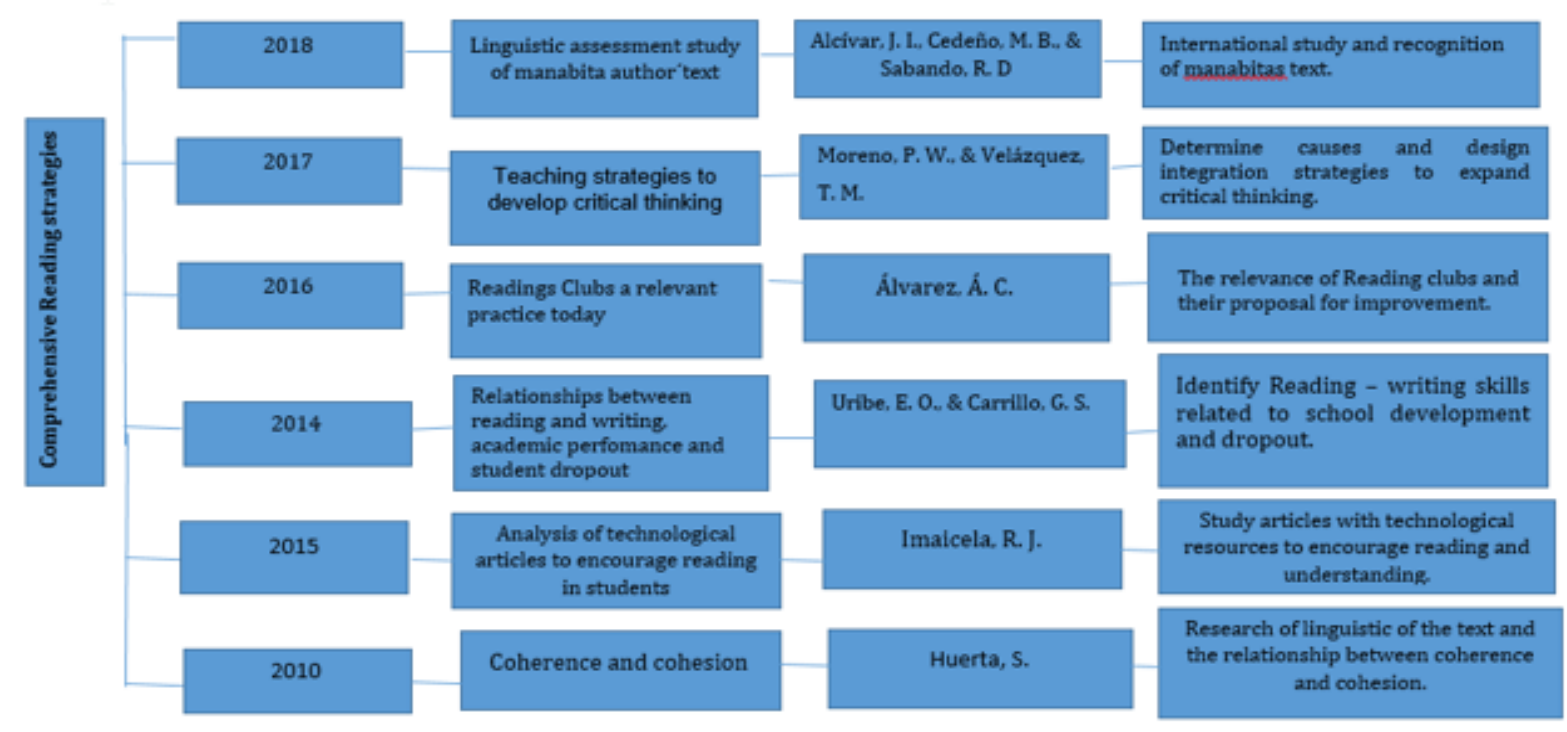

Figure 1. Some authors' strategies

\section{Criteria figures of the authors}

In Figure 1, the most relevant strategies that several authors expose to achieve a comprehensive reading are highlighted, linguistics is investigated in the texts, which These are the reasons why students fail to elucidate the narratives in a book in-depth, how to use images and graphics to tell a story, how to research with the help of the internet and analyze an article perfecting our lexicon and expanding our knowledge, The gestures we use and read in reading groups are excellent strategies for the discussion and interpretation of books.

\section{Conclusion}

Reading does not necessarily mean understanding what has been read, the words must be analyzed to avoid repeating as a recording without obtaining any meaning, we must avoid accelerating the rate in which we read, so that our mind can process the information that is being received, On some occasions and depending on the book, the reading is accompanied by images or graphics that can be representative so that understanding flows more easily, the vocal accents we use when reading are very important because they show the emphasis that the author intends to convey. During the reading period, we can use help means such as concept maps, SPRI (Situation, Problem, Resolution, Information) necessary to make a reflexive reading, knowing linguistic norms is very helpful as knowing how to identify when it is applied and the interpretation that it is given for different contexts, whether narrative, literary or school texts, a hypothesis must be created to previously analyzing the solutions involved in reading.

The active intervention of the teacher is key for students to be motivated, the vocal presentation with which a reading begins invites to keep pace with the story, the formation of reader clubs creates a collaborative and actively participatory environment, each approach It is established individually by the student, the imagination is part of each person, therefore the reading comprehension will never be the same even when the same book is analyzed, the age to read has not been established, we must demand more from our brain, feed it with the knowledge that is manifested in the books, being tireless examiners of the unknown Finally, externalize what has been learned.

Alava, R. A. Q., Laz, E. M. S. A., Palmac, J. K. T., \& Parrales, E. B. A. (2020). Importance of comprehensive reading: its value in basic. International Research Journal of Engineering, IT \& Scientific Research, 6(3), 1-8. https://doi.org/10.21744/irjeis.v6n3.914 
Conflict of interest statement

The authors declared that they have no competing interests.

Statement of authorship

The authors have a responsibility for the conception and design of the study. The authors have approved the final article.

\section{Acknowledgments}

My sincere thanks to Dr. Esthela San Andrés for her collaboration and contributions of knowledge in the advancement of the article, I extend my gratitude to the publishing house where this research will be published, which will contribute with relevant data for students and teachers of many educational institutions. Just as I am sure it will be of interest and educational support for professors interested in reading. 


\section{References}

Aksan, N., \& Kisac, B. (2009). A descriptive study: Reading comprehension and cognitive awareness skills. Procedia-Social and Behavioral Sciences, 1(1), 834-837. https://doi.org/10.1016/j.sbspro.2009.01.149

Alcívar, J. I., Cedeño, M.B., \& Sabando, R.D. (2018). Study of Linguistic Assessment of Authors' Texts Manabitas. Multidisciplinary Scientific Magazine.

Álvarez, Á. C. (2016). Reading clubs A relevant practice today? Filo Digital, 35, 91-106.

Anmarkrud, Ø., \& Bråten, I. (2009). Motivation for reading comprehension. Learning and Individual Differences, 19(2), 252-256. https://doi.org/10.1016/j.lindif.2008.09.002

Beske, P., Land, A., \& Seuring, S. (2014). Sustainable supply chain management practices and dynamic capabilities in the food industry: A critical analysis of the literature. International journal of production economics, 152, 131143. https://doi.org/10.1016/j.ijpe.2013.12.026

Choudhury, S., \& Black, J. M. (1993). Mate-selection behaviour and sampling strategies in geese. Animal Behaviour, 46(4), 747-757. https://doi.org/10.1006/anbe.1993.1252

Cuéllar-Franca, R. M., \& Azapagic, A. (2015). Carbon capture, storage and utilisation technologies: A critical analysis and comparison of their life cycle environmental impacts. Journal of CO2 utilization, 9, 82-102. https://doi.org/10.1016/j.jcou.2014.12.001

Dietrich, J., Dicke, A. L., Kracke, B., \& Noack, P. (2015). Teacher support and its influence on students' intrinsic value and effort: Dimensional comparison effects across subjects. Learning and Instruction, 39, 45-54. https://doi.org/10.1016/j.learninstruc.2015.05.007

Duque, A.C., Ovalle, P.A., \& Bastidas, F.A. (2011). Comprehensive reading of narrative texts in first readers in contexts of interaction in the classroom: a strategy for training in values. Thresholds (22), 15.

Estévez, M.B. (2018). Transformations: From comprehensive reading to the development of creativity: an aulic experience. Doors Open (N. 13).

Flores, H.V. (2015). Influence of sustained attention on comprehensive reading in boys and girls of 8 years of age. Quito: Central University of Ecuador.

Hendrickx, M. M., Mainhard, M. T., Boor-Klip, H. J., Cillessen, A. H., \& Brekelmans, M. (2016). Social dynamics in the classroom: Teacher support and conflict and the peer ecology. Teaching and Teacher Education, 53, 30-40. https://doi.org/10.1016/j.tate.2015.10.004

Huerta, S. (2010). Coherence and cohesion. Herencia, 2(2), 78.

Joyce, H. D., \& Early, T. J. (2014). The impact of school connectedness and teacher support on depressive symptoms in adolescents: A multilevel analysis. Children and youth services review, 39, 101-107. https://doi.org/10.1016/j.childyouth.2014.02.005

Knorr, P. E. (2012). Strategies for addressing texts. The Wac Journal, 15-37.

Lawton, C. A. (1996). Strategies for indoor wayfinding: The role of orientation. Journal of environmental psychology, 16(2), 137-145. https://doi.org/10.1006/jevp.1996.0011

Logan, S., Medford, E., \& Hughes, N. (2011). The importance of intrinsic motivation for high and low ability readers' reading comprehension performance. Learning and Individual Differences, 21(1), 124-128.

Maimun, M., Mandala, H., \& Arifuddin, -. (2018). Ideology in tempo magazine advertising: a critical discussion analysis. International Research Journal of Management, IT and Social Sciences, 5(6), 40-51. https://doi.org/10.21744/irjmis.v5n6.336

Moreno, P.W., \& Velázquez, T.M. (2017). Didactic Strategy to Develop Thought. REICE Iberoamerican Magazine on Quality, Efficiency and Change in Education, 2(15), 21.

Nurmi, J. E., Onatsu, T., \& Haavisto, T. (1995). Underachievers' Cognitive and Behavioural Strategies-SelfHandicapping at School. Contemporary Educational Psychology, 20(2), 188-200. https://doi.org/10.1006/ceps.1995.1012

Padilla, B.E., \& Cordova, P.A. (2016). Strategies to motivate the comprehensive reading, children of 7 th grade parallel $b$ of the basic education school Dr. Matilde Hidalgo de Procel No. 1 of the city of Loja, San Pedro neighborhood in the 2013-2014 school period, 184. Loja: University of Loja Repository.

Palomeque, C.E. (2012). Comprehensive reading techniques in the teaching-learning process, 159. EQUINOCCIAL TECHNOLOGICAL UNIVERSITY. FACULTY: DISTANCE EDUCATION.

Sánchez, O.J., \& Brito, G.N. (2015). Development of communication skills through critical reading, creative writing and oral expression. (UA Caribe, Ed.) Encounters., 13(2), 117-141. https://doi.org/10.15665/re.v13i2.502

Alava, R. A. Q., Laz, E. M. S. A., Palmac, J. K. T., \& Parrales, E. B. A. (2020). Importance of comprehensive reading: its value in basic. International Research Journal of Engineering, IT \& Scientific Research, 6(3), 1-8. https://doi.org/10.21744/irjeis.v6n3.914 
Sivarajah, U., Kamal, M. M., Irani, Z., \& Weerakkody, V. (2017). Critical analysis of Big Data challenges and analytical methods. Journal of Business Research, 70, 263-286. https://doi.org/10.1016/j.jbusres.2016.08.001

Solís, J.M. (2016). Comprehensive reading and oral expression in the students of the Educational Unit "Pedro Fermín Cevallos" city of Ambato, Tungurahua Province, 153. Ambato: Technical University of Ambato. Faculty of Humanities and Education. Career of Basic Education.

Uribe, E.O., \& Carrillo, G.S. (2014). Relationship between reading and writing, academic performance and student dropout. Unilibre Cali, 10(2), 272-285. 